
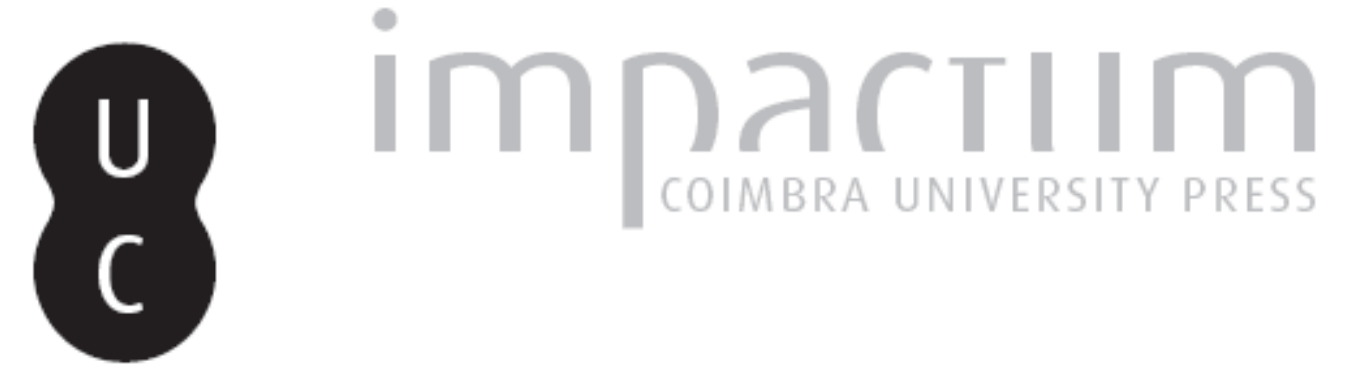

\title{
Fenomenologia da intersubjectividade: perspectivas transcendentais e empíricas
}

\author{
Autor(es): $\quad$ Gallagher, Shaun
}

Publicado por: Faculdade de Letras da Universidade de Coimbra, Instituto de Estudos

URL

persistente:

URI:http://hdl.handle.net/10316.2/29451

DOI:

DOI:http://dx.doi.org/10.14195/0872-0851_42_8

Accessed : $\quad$ 26-Apr-2023 11:52:49

A navegação consulta e descarregamento dos títulos inseridos nas Bibliotecas Digitais UC Digitalis, UC Pombalina e UC Impactum, pressupõem a aceitação plena e sem reservas dos Termos e Condições de Uso destas Bibliotecas Digitais, disponíveis em https://digitalis.uc.pt/pt-pt/termos.

Conforme exposto nos referidos Termos e Condições de Uso, o descarregamento de títulos de acesso restrito requer uma licença válida de autorização devendo o utilizador aceder ao(s) documento(s) a partir de um endereço de IP da instituição detentora da supramencionada licença.

Ao utilizador é apenas permitido o descarregamento para uso pessoal, pelo que o emprego do(s) título(s) descarregado(s) para outro fim, designadamente comercial, carece de autorização do respetivo autor ou editor da obra.

Na medida em que todas as obras da UC Digitalis se encontram protegidas pelo Código do Direito de Autor e Direitos Conexos e demais legislação aplicável, toda a cópia, parcial ou total, deste documento, nos casos em que é legalmente admitida, deverá conter ou fazer-se acompanhar por este aviso. 


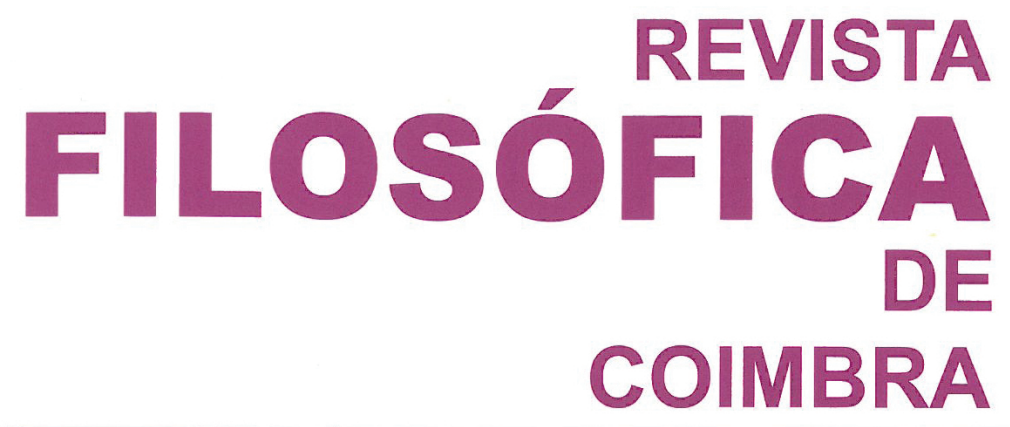

vol. 21 - número 42 - outubro 2012

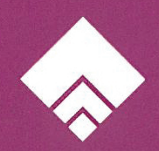




\title{
FENOMENOLOGIA DA INTERSUBJECTIVIDADE: PERS- PECTIVAS TRANSCENDENTAIS E EMPÍRICAS ${ }^{1}$
}

SHAUN GALLAGHER

\begin{abstract}
After reviewing the phenomenological analyses of transcendental intersubjectivity and being-with (Mitsein) in Husserl and Heidegger, respectively, I explore the relationship between such analyses and recent empirical research in the developmental and cognitive sciences, including dynamic systems modeling. I suggest that if we bring the insights of this recent literature back to the question of the transcendental analysis, then in at least one regard, namely, with respect to primary intersubjectivity, it supports Husserl's account and reveals a problem with Heidegger's analysis of being-with.
\end{abstract}

Keyterms: intersubjectivity, social cognition, theory theory, simulation theory, interaction theory, Husserl, Heidegger, being-with.

Sinopse: Depois de revisitar as análises fenomenológicas da intersubjectividade transcendental e do ser-com (Mitsein) em Husserl e Heidegger respectivamente, exploro a relação entre estas análises e a investigação empírica recente nas ciências cognitivas e do desenvolvimento, incluindo a modelação dinâmica de sistemas. Defendo que se trouxermos estes resultados desta literatura recente para a questão da análise transcendental, então, ao menos num aspecto, a saber, no que se refere à intersubjectividade primária, a tese de Husserl recebe apoio, e é revelado um problema com a análise do ser-com de Heidegger.

Palavras-chave: intersubjectividade, cognição social, teoria-teoria, teoria da simulação, teoria da interacção, Husserl, Heidegger, ser-com.

1 O meu trabalho neste artigo foi apoiado em parte pelo projecto Marie Curie, Towards an embodied science of intersubjectivity (TESIS) [Para uma ciência corporalizada da intersubjectividade] e, em parte, pelo programa Erasmus Mundus EuroPhilosophie que permitiu a minha estadia como Professor visitante na Universidade de Coimbra, Portugal, em Março de 2012. Agradeço ao Prof. Diogo Ferrer a tradução do inglês. 


\section{Intersubjectividade transcendental}

Na sua Quinta Meditação (1960), Husserl desenvolve uma análise transcendental de como experienciamos a outra pessoa. A análise reivindica validade universal, na medida em que é proposta como uma intelecção eidética da estrutura de toda a experiência possível dos outros.

$\mathrm{Na}$ sua análise, Husserl defende várias teses importantes. Em primeiro lugar, que qualquer experiência intersubjectiva de empatia pressupõe uma experiência primária e não-intersubjectiva da diferença entre o meu corpo psico-físico e as 'coisas externas'. Na experiência de um sujeito, um organismo animado é "isolado como único" (Husserl 1960, p. 97) devido ao facto de que o sujeito só pode atribuir experiências hiléticas (por exemplo, sensações tácteis ou sensações de calor e de frio) ao seu próprio corpo. Este carácter único é também suportado pelo facto de que o sujeito tem a capacidade de "reger e governar" este corpo "imediatamente" (Husserl 1960, p. 97), o que confere ao sujeito um sentido básico do 'eu posso'. Em texto anteriores, Husserl tinha acentuado que todo o movimento corporal é acompanhado por sensações cinestésicas que pertencem unicamente ao organismo que realiza o movimento. Todas as experiências como esta, analisadas mais tarde por Merleau-Ponty em termos de esquema corporal, ajudam a distinguir o organismo do sujeito de tudo o resto.

Em segundo lugar, a experiência da outra pessoa baseia-se numa aperсеpção (Husserl 1960, p. 110). A apercepção é um modo de experiência no qual algo que não é explicitamente apresentado é, no entanto, de certo modo percepcionado. Por exemplo, quando percepciono visualmente a maçã sobre a mesa à minha frente, vejo, literalmente, somente um lado dela, e não a posso ver inteira de uma só vez. Contudo, experiencio-a como uma maçã completa, e não somente como uma fachada unilateral de uma maçã. Assim, tenho uma espécie de experiência das partes da maçã que, literalmente, não vejo - a maçã é 'presentificada' ['appresented'] como um todo. De modo similar, a outra pessoa é apresentada incompletamente, não só no que respeita ao seu corpo, que de cada vez só posso ver incompletamente, como também no que respeita às suas experiências interiores que, literalmente, não posso de todo ver. E, no entanto, quando percepciono outra pessoa, esta é experienciada como tendo as suas próprias experiências, uma vida mental interior. Percepciono o outro como um organismo animado - percepciono-o não como um organismo que se comporta simplesmente de uma certa maneira, mas como um organismo que tem uma vida interior. Esta vida interior é presentificada, experienciada de algum modo, embora de uma maneira diferente de como experiencio a minha própria vida interior. $\mathrm{O}$ outro não me é dado à maneira da primeira pessoa, tal como me é dada a minha própria experiência. 
A minha auto-experiência é assimétrica em relação à minha experiência do outro. Esta é uma diferença importante entre eu próprio e o outro. A incompletude do outro, neste aspecto, é precisamente a sua presença como outro (ver Levinas 1969).

Em terceiro lugar, esta apercepção do outro como organismo animado baseia-se numa associação passiva, um 'emparelhamento' entre a minha experiência do corpo do outro e do meu próprio. O conceito de emparelhamento é central para a análise de Husserl. O emparelhamento baseia-se numa similaridade percepcionada entre eu e o outro. Esta similaridade, porém, não é algo de descoberto num acto de comparação, pelo qual, por exemplo, olho para mim mesmo, depois para o outro e concluo então que temos uma aparência semelhante. Não é o resultado de alguma espécie de analogia que estabeleço entre mim mesmo e um outro, pela qual, analogicamente, eu infira que o outro tem de ser similar a mim. Nem se trata tão-pouco de uma similaridade baseada nas aparências dos nossos corpos. Os fenomenólogos defendem que uma similaridade neste sentido falha, uma vez que a minha consciência do meu próprio corpo, em termos proprioceptivos e agenciais, é muito diferente da minha consciência, visual e externa, do corpo da outra pessoa. Poder-se-ia argumentar, com base em investigações psicológicas recentes, que a percepção é de modalidade cruzada [cross-modal] e que os sistemas visuais e proprioceptivos codificam as coisas na mesma 'linguagem' (veja-se Gallagher e Meltzoff 1996), de tal modo que há uma certa similaridade que atravessa daquilo que vejo visualmente para o que sinto proprioceptivamente. Poder-se-ia pensar isto também, nos termos próprios de Husserl, como uma similaridade cinestésica ou, em termos neuro-científicos contemporâneos, de uma ressonância motora que é suscitada - ou seja, uma activação do meu próprio sistema quando vejo as acções de outras pessoas, ocasionada por neurónios-espelho. ${ }^{2}$ Merleau-Ponty falaria de processos que envolvem esquemas corporais e a que se referiu como uma intercorporalidade, que descreve como se segue: "entre este meu corpo fenoménico e o de outrem tal como o vejo de fora, existe uma relação interna que causa o aparecer do outro como a completação do sistema" (Merleau-Ponty 1962, p. 352). Em qualquer caso, Husserl interpreta este tipo de emparelhamento como uma forma de empatia: uma experiência na qual a vida mental de outra pessoa é automaticamente apercebida, antes que ocorra qualquer decisão voluntária ou interpretação.

2 Os neurónios-espelho são neurónios que são activados quando (1) realizo uma acção intencional, tal como apanhar uma bebida, e (2) quando vejo alguém realizar uma tal acção. Para uma boa análise de como a fenomenologia de Husserl se relaciona com a neurociência dos neurónios-espelho, veja-se Zahavi (2012). 
Husserl defende, finalmente, que a apercepção de outra pessoa é verificada numa experiência contínua caracterizada por um comportamento harmonioso ou consistente, naquilo que é claramente um padrão narrativo. A minha experiência de outrem como um organismo animado, ou seja, como um organismo com uma vida interior, colapsa se o seu comportamento (ou, gostaria de acrescentar, a narrativa) é demasiado discordante (Husserl 1960, p. 114). Faz todo o sentido pensar que o processo de emparelhamento e a empatia, tal como Husserl os descreve, podem ser interrompidos por um tal comportamento.

Importa fazer notar nesta análise que nem a apercepção nem o emparelhamento requerem uma inferência. Ou seja, não entramos num processo cognitivo extra-perceptivo quando procuramos descobrir quais são os estados mentais de outra pessoa. É claro que Husserl pretende que esta seja uma análise transcendental, e não necessariamente uma tentativa de explicar como chegamos a compreender outra pessoa em alguma situação particular - algo que pode envolver variações dentro da linha estritamente eidética aqui definida. Mas Husserl sugere também que "toda a análise ou teoria fenomenológica transcendental [...] pode ser reproduzida no domínio natural quando abandonamos a atitude transcendental" (Husserl $1960, \S 54)$. Esta passagem a uma atitude não-transcendental, ou natural, constituiria o começo de uma psicologia fenomenológica.

Gostaria de fazer notar um outro aspecto importante na noção de Husserl de uma intersubjectividade transcendental. Husserl defende que a intersubjectividade tem uma relevância directa para o conceito de intencionalidade. A minha experiência intencional do mundo dá-me um sentido de objectividade que está ligada ao nível do acesso intersubjectivo. O mundo não existe só para mim, e isto fala-nos de um certo sentido indesmentível do intersubjectivo.

A intersubjectividade transcendental é o absoluto e único fundamento ontológico auto-suficiente a partir do qual tudo o que é objectivo (a totalidade das entidades objectivamente reais, mas também todo o mundo objectivo ideal) retira o seu sentido e validade (Husserl 1977, p. 344).

A objectividade e a transcendência do mundo - a sua alteridade, o facto de que não se deixa reduzir apenas a um conjunto de ideias na minha mente - é constituída pela sua dimensão intersubjectiva. $\mathrm{O}$ mundo não é somente o meu mundo, uma vez que é experienciado por outros segundo modos que não se reduzem à minha própria experiência dele. $\mathrm{O}$ mundo escapa à minha percepção completa, e é algo que é necessário para além da minha própria existência, posto que se abre a outras perspectivas de que somente me posso aperceber. 
Assim, tudo o que é objectivo, que está perante mim na experiência e, primariamente, na percepção tem um horizonte aperceptivo de experiências possíveis, minhas e de outros. Em termos ontológicos, toda a aparição que tenho é, desde o seu início, parte de uma totalidade aberta, infinita, e não explicitamente realizada de aparições possíveis do mesmo, e a subjectividade que pertence a esta aparição é uma intersubjectividade aberta (Husserl 1973, p. 289).

Sartre é bem conhecido por retirar temas existenciais dramáticos a partir destas intuições. Ele sintetiza a perspectiva de Husserl como se segue: "cada objecto, longe de ser constituído, como para Kant, por uma simples relação com o sujeito, aparece na minha experiência concreta como polivalente; é originariamente dado como possuindo sistemas de referência a uma pluralidade indefinida de consciências" (Sartre 1956, p. 229). Enquanto que, para Husserl, esta é uma verdade transcendental, em que quase não reparamos, para Sartre é uma alteração ontológica, sentida como estranha, na experiência do mundo. Sartre sugere que a minha relação com as coisas sofre uma mudança fundamental quando experiencio outrem a observar essas mesmas coisas. Quando, por exemplo, outra pessoa se dirige para o parque onde estou sentado, então

[...] subitamente, apareceu um objecto que me roubou o mundo. Tudo permanece no seu lugar; tudo continua a existir para mim, mas está atravessado por um ponto de fuga invisível e fixado na direcção de um novo objecto. A aparição de outrem no mundo corresponde, assim, a um deslocamento fixo de todo o universo, a uma descentração do mundo que mina a centralização que eu simultaneamente opero (Sartre 1956, p. 255).

O poder da perspectiva do outro torna-se ainda mais motivador de angústia quando o seu olhar cai sobre mim. Retornaremos, mais abaixo, à importância da faculdade do outro de me ver - de me tomar como objecto - quando atendermos à questão da cognição social.

\section{Ser-com os outros}

Heidegger oferece uma concepção diferente da intersubjectividade, ou do que denomina "ser-com" (Mitsein), concepção que se distancia da aparente imediatez do emparelhamento corpo-com-corpo ou do sentido de que o outro pode ser ocasião para ansiedade existencial. Em vez disso, segundo Heidegger, o outro é afinal a fonte de uma conformidade excessivamente adequada. A intersubjectividade como fonte transcendental da objectividade só poderia desempenhar um papel derivado, e não instituidor. 
Não há dúvida de que Heidegger entende o ser-com como uma dimensão importante da existência humana, e a maior parte dos comentadores insiste na centralidade desta noção de ser-com os outros (por exemplo Wheeler 2005, p. 149). O ser-com é um aspecto existencial do ser-aí, igualmente primordial ou co-original com o ser-no-mundo (1962, p. 149/114; também p. 153/117). Heidegger evita o termo 'intersubjectividade', uma vez que este parece significar a ideia tradicional (e cartesiana) de que existe um sujeito individual isolado $\mathrm{A}$, perante um segundo sujeito individual isolado $\mathrm{B}$, de tal modo que o problema fica definido como sendo o de saber de que modo A pode compreender B e vice-versa. Esta é simplesmente a maneira errada de pôr o problema (por exemplo, Heidegger 1988, pp. 237-238). Do mesmo modo, Heidegger não utilizaria o termo 'cognição social' dado que este parece definir o problema como envolvendo cognição ou conhecimento. Em coerência com a sua análise do ser-no-mundo, Heidegger defende que a cognição, e preocupações a ela associadas acerca da objectividade epistémica, são questões secundárias. Ser-com os outros é algo de mais básico e existencial do que isto - ou seja, tem um significado ontológico mais básico do que pode ser capturado pelo conceito de cognição, ou pela ideia de conhecer outras mentes. A despeito destas questões críticas do vocabulário, as análises ontológicas de Heidegger têm algo de importante a dizer-nos sobre os processos intersubjectivos básicos e, consequentemente, sobre a cognição social.

Dizer que o ser-com é igualmente primordial ou co-original ao ser-no-mundo significa que ele é parte da estrutura existencial da existência humana (Dasein), e não um acrescento; não é algo de supletivo ao Dasein. Ser-com não significa que o Dasein é primeiro no-mundo, e depois, por causa disso, está com os outros. Heidegger acentua claramente este ponto. Ser-com, como uma estrutura existencial do Dasein, não tem na verdade nada que ver com o facto de que possa haver ainda outras pessoas no mundo. $\mathrm{O}$ facto de que outros estão no mundo só tem significado porque o Dasein é ser-com, e não o contrário. Ainda que lhe aconteça estar só, o Dasein continua a ser-com - e "unicamente como ser-com pode o Dasein estar só" (Heidegger 1988, p. 238), ou, na verdade, solitário. Heidegger acentua este ponto tão fortemente que parece que ser-com não depende, como tal, de existirem outros; o Dasein "está longe de se tornar ser-com porque algum outro se mostra de facto" (Heidegger 1988, p. 239).

Este ser-com-o-outro não é um resultado que se adiciona à ocorrência de diversos outros, não é um epifenómeno de uma multiplicidade de Dasein's, algo de suplementar que só poderia ocorrer por força de um certo número. Pelo contrário, é justamente porque o Dasein, como ser-no-mundo, é por si mesmo ser-com que existe algo como um ser-com-o-outro (Heidegger 1985, p. 239). 
Dreyfus, no seu comentário a Ser e Tempo (Dreyfus 1991, p. 149) põe a coisa deste modo: "ser-com continuaria a ser uma estrutura do meu sendo-Dasein [Daseining] mesmo que todos os outros Dasein's tivessem sido exterminados".

Segundo Heidegger, o encontro do Dasein com outros acontece "por via do mundo" (Heidegger 1988, p. 239). Ou seja, é por intermédio dos contextos pragmáticos quotidianos que o Dasein encontra o outro. O lidar do Dasein com o seu ambiente fornece uma referência imediata a outrem. Por exemplo, uma obra de um artesão faz-nos encontrar não só a coisa, mas também a pessoa que a fez e a pessoa a quem ela é destinada. Tal é a natureza do encontro original e inicial com os outros. Chegamos a eles inevitavelmente envolvidos, do mesmo modo como estamos envolvidos em contextos pragmáticos: "deveria notar-se aqui que o tipo de encontro mais próximo com outrem está na direcção do mesmo mundo no qual está absorvido o cuidado do Dasein" (Heidegger 1988, p. 241). ${ }^{3}$ Deparamos com pessoas que já estão-no-mundo, neste sentido de estarem envolvidas com as coisas do mesmo modo. O Dasein compreende-se a si, e aos outros, "em primeiro lugar, e principalmente, a partir do seu mundo" (Heidegger 1962 , p. $156 / 120)$.

O facto de que o Dasein está no-mundo, e que o mundo é partilhado com outros ajuda a responder à questão sobre 'quem' é o Dasein. Heidegger afasta a resposta das soluções tradicionais do "eu", si-mesmo (self), espírito ou alma. "Pode bem ser que o 'quem' do Dasein quotidiano não seja justamente "eu mesmo"” (1962, p. 150/115). Pelo contrário, Heidegger sugere que o 'impessoal' (das Man) constitui uma parte importante da identidade do Dasein. Ou seja, o Dasein é de tal modo tomado pela dimensão social e pela dominação dos outros que se perde numa inautenticidade social, na qual se compreende como sendo o mesmo que qualquer outro.

Em contraste com a atitude da 'manualidade circunspectiva' em relação ao mundo do 'cuidado', a atitude do Dasein em relação a outrem é de "solicitude" (Heidegger 1962, p. 155/119; 157/122). Heidegger explicita o que denomina de "modos deficientes da solicitude", que incluem a variedade de modos com que sem grande atenção passamos uns pelos outros nas nossas idas e vindas quotidianas. A solicitude comporta também duas manifestações positivas, não-indiferentes. Na estranha terminologia de Heidegger, estas podem "substituir-se" (einspringen) e "antecipar-se"

3 Heidegger continua a sublinhar que este modo particular de ser-no-mundo co-determina todos os outros modos do Dasein: "em razão deste comum [mithaften] ser-no-mundo, o mundo é sempre já o mundo que partilho com outros. O mundo do Dasein é um mundo-com. Ser-em é ser-com outros. O seu ser-em-si intra-mundano é Dasein-com [Mitdasein]" (1962, p. 155/118). 
(vorausspringen). (1962, p. 158-159/122) Quando nos 'substituímos', assumimos, no lugar de outro, aquilo de que ele ou ela deveria cuidar. Este é um acto de domínio que conduz à dependência, ainda que seja feito silenciosamente, e que o outro não se aperceba inteiramente do que aconteceu. Como tal, é equivalente ao que Sartre chamou mais tarde a 'má fé' nas nossas relações com os outros. O "antecipar-se", diz Heidegger, "é parte essencial do autêntico cuidado - ou seja, faz parte da existência de outrem, e não de um 'algo' de que este cuide, e ajuda o outro a tornar-se transparente no seu cuidado, e livre para este" (1962, p. 158/122; v. 344/297-98).

Heidegger diz-nos que as nossas interacções quotidianas ocorrem entre estes dois pólos de solicitude positiva. Indica, em seguida, que o substituir-se ocorre frequentemente entre aqueles que "têm uma ocupação comum", e a relação "alimenta-se muitas vezes somente da desconfiança". Inversamente, quando eles (nós e outros) assumem um projecto comum, podem vir a estar "ligados autenticamente", o que cria o tipo correcto de possibilidades e "liberta o outro na sua liberdade para si mesmo" (Heidegger 1962, p. 159/122). Em todo o caso, quer nos 'substituamos', quer nos 'antecipemos' aos outros, estamos já envolvidos com eles na medida em que estamos já pragmaticamente envolvidos no mundo (Heidegger 1962, p. 160/123).

Heidegger rejeita a ideia de que chegamos a compreender a outra pessoa primeiramente de um modo intelectual, ou que as nossas relações com eles sejam primariamente cognitivas.

Porque a existência do Dasein é ser-com, a sua compreensão do ser implica já a compreensão dos outros. Esta compreensão, como toda a compreensão, não é um dado resultante do conhecimento, mas um modo de ser existencial originário sem o qual, antes de tudo o mais, nenhum dado ou conhecimento é possível (Heidegger 1962, p. 160/123).

O modo como uma análise transcendental é organizada tem alguma importância para o modo como, na sequência dela, se pode pensar o empírico. Isto torna-se claro se contrastamos as análises das nossas relações com os outros segundo Husserl e segundo Heidegger. Embora ambos concedam uma clara prioridade transcendental à intersubjectividade ou ao ser-com, para Husserl o outro é um pré-requisito necessário para a experiência do mundo como real e objectivo, ao passo que tal não parece ser o caso segundo Heidegger. O Dasein é ser-com e está no-mundo mesmo que não haja outros no mundo. Em termos do modo como isto resulta na análise dos nossos encontros quotidianos, segundo a tese de Heidegger, o 
Dasein só encontra os outros num mundo onde já está pragmaticamente envolvido, ao passo que segundo a tese de Husserl, no que toca à ordenação do mundo, a intersubjectividade tem uma clara primazia em relação a qualquer coisa que se possa considerar como pragmática, e tem certamente a primazia em relação à percepção dos objectos. Enquanto que Heidegger pode concordar com esta última cláusula, a sua análise sugere que somente encontramos os outros num estádio que já está organizado pelos nossos envolvimentos pragmáticos; o confronto pragmático com o mundo parece já estar no seu lugar antes de nos depararmos com os outros, não obstante a insistência de Heidegger no carácter igualmente primordial do ser-com e do ser-no-mundo (Gallagher e Jacobson, no prelo). Isto leva Gadamer a dizer que "o Mitsein para Heidegger foi uma concessão que ele teve de fazer, mas em que nunca realmente acreditou [...]. [T]rata-se, na verdade, de uma ideia muito pálida do outro [...]" (Gadamer 2004, p. 23). ${ }^{4}$

Ao pretender dar primazia ao intersubjectivo, Husserl é conduzido à ideia de uma experiência originária do outro. Esta ideia pretende resolver um problema, delineado do modo mais claro por Dan Zahavi. "Em condições normais, experiencio aquilo que acidentalmente experiencio sozinho (por exemplo, este computador onde agora escrevo) como transcendente, objectivo e real, apesar de não estar simultaneamente a experienciar este objecto como sendo experienciado por outros" (Zahavi 2003, p. 116). Husserl admite isto e sugere mesmo que se toda a população do mundo fosse varrida (para retomar a frase de Dreyfus), o sujeito solitário da experiência experienciaria ainda um mundo objectivo. Isto parece colocá-lo numa posição semelhante à de Heidegger, que sugere que o ser-com do Dasein não depende de haver algum outro no mundo. Husserl, contudo insiste em que isto só pode ser o caso após um encontro primeiro, instituidor. O problema resolve-se "se se diferencia entre a nossa experiência primitiva de outros - que torna de uma vez por todas possível a objectividade, a realidade e a transcendência, transformando assim permanentemente as nossas categorias da experiência - e todas as experiências subsequentes

${ }^{4}$ Esta é uma tese controversa, mas Gadamer não está só. O discípulo de Heidegger, Karl Löwith (1928), por exemplo, sugeriu, um ano depois da publicação de Ser e Tempo, que Heidegger ignorou na sua análise o papel do contacto interpessoal directo. Biswanger (1962) fez uma crítica semelhante e defendeu que a ideia de que o Dasein é ser-com o deixou com um "nó de questões por resolver" (1962, p. 6). Um outro estudioso de Heidegger, Otto Pöggeler, comentou que "está certamente fora de questão o facto de que a investigação de Heidegger do ser social é um dos questionamentos mais insatisfatórios da sua obra. Isto tem de ser dito, ainda que se considere que Heidegger nunca chegou a elaborar concretamente esta questão; que só a tratou com a intenção de fazer 'ontologia fundamental"” (1989, p. 251). 
dos outros" (Zahavi 2003, p. 116). Aparentemente, mesmo se eu fosse impedido de ter essas outras experiências subsequentes dos outros, seria ainda assim capaz de experienciar o mundo como transcendente e objectivo, por força de uma experiência do outro instituidora ou originária.

Qual o alcance de tais experimentações transcendentais do pensar no que respeita aos nossos encontros reais com os outros? Gostaria de ver a questão ao contrário. Pode um exame dos nossos encontros quotidianos com os outros - incluindo análises fenomenológicas e empíricas - contribuir de algum modo para tais considerações transcendentais? Podem ajudar-nos a decidir sobre as diferenças entre Husserl e Heidegger a propósito destas questões ou, ao menos, a esclarecer de que diferenças se trata? Segundo algumas concepções, estudos recentes da cognição social podem fazer exactamente isso.

\section{Concepções padrão sobre a cognição social}

Há duas abordagens padrão dominantes das questões da cognição social na filosofia da mente, na psicologia e nas disciplinas das ciências cognitivas: a 'teoria-teoria' (TT) e a teoria da simulação (TS). Na verdade, muito da literatura sobre a cognição social se ocupa do debate entre esta duas teorias. Ambas cabem no capítulo da 'teoria da mente' (TdM), que se foca na explicação da nossa capacidade de 'ler a mente', isto é, de atribuir estados mentais a outros. A atribuição de estados mentais, como crenças ou desejos, segundo a TdM, permite-nos explicar e prever as acções de outras pessoas. A TT defende que compreendemos os outros fazendo inferências sobre estados mentais com base no nosso conhecimento da psicologia popular [folk psychology], ou seja, a teoria do senso comum sobre como as pessoas se comportam normalmente à luz das suas crenças e desejos (veja-se, por exemplo, Carruthers 2009). A TS defende, pelo contrário, que não temos necessidade de uma teoria psicológica popular, porquanto dispomos de um modelo, a saber, a nossa própria mente, que podemos usar para simular os estados mentais da outra pessoa. Pomo-nos na pele da outra pessoa e formulamos o que devem ser as suas crenças ou desejos, com base no que seriam os nossos naquela situação, e projectamos então essas crenças e desejos na outra pessoa (veja-se, por exemplo, Goldman 2006). A descrição do processo de simulação por Alvin Goldman é como se segue.

Em primeiro lugar, a atribuidora cria nela mesma estados simulados que pretendem corresponder aos do alvo [da observação]. Noutras palavras, a atribuidora tenta colocar-se 'na pele' do alvo. O segundo 
passo é alimentar com estes estados simulados iniciais [por exemplo, crenças] algum mecanismo da psicologia da própria atribuidora [...] e deixar que este mecanismo opere sobre os estados simulados, de modo a gerar um ou mais novos estados [por exemplo, decisões]. Terceiro, a atribuidora transfere o estado resultante para o alvo [...] [por exemplo, inferimos ou projectamos a decisão para a outra mente] (Goldman 2005, pp. 80-81).

A simulação é frequentemente considerada uma forma de empatia, ou um modo de explicar a empatia (Gallese 2003; Goldman 2006; Steuber 2006). Neste contexto, a TS recebeu apoio da pesquisa neuro-científica sobre os neurónios-espelho. Dado que a observação da acção da outra pessoa activa o meu próprio sistema motor, a tese é que este tipo de ressonância ao espelho é uma espécie de empatia ou de simulação. Os simulacionistas distinguem em conformidade entre processos empáticos automáticos de nível inferior baseados em simulações neurais sub-pessoais e processos de nível elevado, mais explícitos, que requerem simulação ou empatia consciente ou habitual (Goldman 2006; Steuber 2006).

Tanto para a TT quanto para a TS, o problema é que não temos acesso directo à mente da outra pessoa. Somos, antes de tudo o mais, observadores do comportamento. Quando tentamos compreender as acções dos outros, servindo-nos quer da inferência teorética quer da simulação, fazêmo-lo lendo os processos mentais do outro e, em ambas as teorias, este é o nosso modo primário e geral de explicar ou prever o que os outros fizeram ou farão. ${ }^{5}$

Na medida em que o problema da cognição social é definido no âmbito destas abordagens, trata-se, nos termos de Heidegger, "do fenómeno que mais proximamente se tem em vista quando se considera a problemática teorética de compreender a vida psíquica dos outros"' (Heidegger 1962, p. 161/124). Da perspectiva da fenomenologia, isto enquadra o problema de uma maneira errada. Não encontro os outros como outras mentes ou como problemas teóricos que preciso de explicar; encontro-os em interacções corporalizadas e, frequentemente, como agentes com os quais estou já empenhado em projectos significativos. O significado do comportamento

5 Estes são os termos técnicos na literatura da TT e da TS: 'ler a mente', 'mentalizar', 'explicar' e 'prever', mas não 'compreender'. Considera-se normalmente que a aquisição da capacidade de utilizar a psicologia popular, ou a de empregar rotinas de simulação explícitas ou habituais ocorre com cerca de 4 anos. Considera-se que as crianças não dispõem, antes dessa idade, de uma teoria completa da mente, mas podem dispor de capacidades precursoras que lhes permitem compreender acções ou intenções (ver, por exemplo, Baron-Cohen 1995). 
dos outros e a minha compreensão destes estão directamente ligados às minhas interacções corporalizadas com eles e às situações instrumentais ou sociais nas quais os encontro. Em circunstâncias normais, não problemáticas, não há nenhum outro mistério, nada de extraordinário, oculto, sobre o qual eu precise de teorizar. E tão-pouco necessito de um processo de simulação para superar o hiato entre mim e os outros.

\section{Abordagens fenomenológicas da cognição social}

Abordagens fenomenológicas recentes ${ }^{6}$ de questões acerca da cognição social vieram pôr em causa estas explicações padrão mais estabelecidas da TdM. As abordagens fenomenológicas envolveram tanto uma crítica das diferentes versões da TT e da TS, quanto uma dupla tese positiva acerca da cognição social. A dupla tese apoia-se não só na fenomenologia, mas também na ciência do desenvolvimento, na neurociência social e na teoria da narrativa, e inclui:

(a) Uma tese sobre as formas básicas da intersubjectividade que acentua a interacção face a face em contextos pragmáticos e sociais - isto é por vezes referido como a teoria da interacção (TI);

(b) Uma tese sobre as práticas comunicativas e narrativas que assentam sobre formas básicas da intersubjectividade, mas que também as modulam, e que podem explicar a nossa capacidade adulta mais matizada de cognição social.

As abordagens fenomenológicas põem em causa quatro supostos básicos que inspiram a maior parte das teses padrão da TdM sobre a cognição social.

(1) Mentes ocultas: o problema da cognição social deve-se à nossa falta de acesso aos estados mentais das outras pessoas. Uma vez que não podemos perceber directamente as crenças, desejos, sen-

${ }^{6}$ Refiro-me a abordagens fenomenológicas no plural a fim de incluir aquelas que se servem não só da filosofia fenomenológica como também de teorias enactivas [enactive] da percepção, estudos de desenvolvimento da interacção social e/ou teorias narrativas. Há diversos autores que adoptam estas abordagens da cognição social, mas que dão uma importância diferente a estes diferentes aspectos. Partilham de um consenso geral na sua crítica às abordagens da TdM, mas não estão de acordo nas suas teses positivas. Veja-se, por exemplo, De Jaegher, Di Paulo e Gallagher (2010); Fuchs e De Jaegher (2009); Gallagher (2001; 2004; 2005; 2007; 2008); Gallagher e Hutto (2008); Gallagher e Zahavi (2008); Hobson (1993); Hutto (2008); Ratcliffe (2007); Reddy (2008); Trevarthen (1979). 
timentos ou intenções dos outros, precisamos de algum processo (inferência ou simulação) cognitivo (leitura da mente) para compreender os seus estados mentais.

(2) Leitura da mente por carência: estes processos de leitura da mente são o nosso modo primário, geral, ou assumido por carência, de compreender os outros.

(3) Atitude observacional: a nossa atitude normal quotidiana em relação à outra pessoa é uma atitude de terceira pessoa, observacional. Observamos os seus comportamentos a fim de explicar e prever as suas acções, ou de teorizar ou simular os seus estados mentais.

(4) Individualismo metodológico: compreender os outros depende, em primeiro lugar, de faculdades ou mecanismos cognitivos situados num sujeito individual, ou de processos que têm lugar dentro de um cérebro individual.

Contra (1), as abordagens fenomenológicas defendem que as emoções e intenções das outras pessoas estão manifestas, normal e frequentemente, nos seus comportamentos corporalizados e contextualizados, incluindo as suas vocalizações, gestos, expressões faciais, olhar e posturas determinadas. Podemos, por exemplo, ver se alguém está triste ou zangado pelas suas expressões faciais, ou que pretende fazer algo de específico pela sua postura e movimento. As intenções não são estados mentais escondidos, mas corporalizados na acção do outro, de tal modo que podemos ver a sua intenção - podemos percepcionar as suas intenções motoras e as suas intenções-em-acção. Do mesmo modo, as emoções não são puros estados mentais; são constitutivamente corporalizadas e manifestas de maneiras percepcionáveis. As intenções e as emoções das acções não são corporalizadas de modo abstracto, mas estão sempre contextualizados em situações. É frequente que as circunstâncias nas quais vemos e interagimos com os outros tornem claro porque estão tristes ou zangados, o que tencionam fazer ou qual será o sentido da sua acção determinada. Ademais, contra (2), em quase todos os encontros quotidianos o nosso entendimento dos outros não precisa de ir além do que podemos percepcionar em tais comportamentos e expressões. Ou seja, habitualmente não é necessário nenhuma leitura da mente, embora esta não esteja excluída, por exemplo, em raras ocasiões desconcertantes. Contra (3), de uma perspectiva fenomenológica, não compreendemos os outros assumindo posições observacionais, ou procurando elaborar explicações para o seu comportamento em termos dos seus estados mentais, mas nos contextos de situações partilhadas onde colaboramos, jogamos ou de outro modo nos envolvemos numa interacção com eles. Contra (4), a compreensão social não é tão-pouco redutível a mecanismos situados nas mentes ou 
cérebros individuais (mecanismos da TdM, neurónios-espelho, etc.). Pelo contrário, estão em última instância vertidos em processos de interacção cuja realização requer mais de uma pessoa.

É óbvio que a interacção (e não a observação) desempenha um papel central na TI. Eis uma definição formal:

Interacção: uma acoplagem co-regulada, participada mutuamente por pelo menos dois agentes autónomos, onde a co-regulação e o acoplamento afectam mutuamente os participantes, e que constitui uma organização auto-sustentada no domínio da dinâmica das relações (Ver De Jaegher et al. 2010).

Esta definição envolve a tese robusta de que a interacção, em muitos casos (mas não em todos), constitui a compreensão intersubjectiva, e não contribui apenas causalmente para ela. Se a interacção em tais casos faz da cognição social o que ela é, então ela é mais do que um mero elemento causal. Pode-se encontrar provas para apoiar esta tese robusta em um certo número de disciplinas diferentes.

\section{(a) Estudos do desenvolvimento}

A TI apela a provas dos estudos do desenvolvimento, a começar com a intersubjectividade primária e secundária (Trevarthen 1979; Trevarthen e Hubley 1978). A intersubjectividade primária consiste em capacidades sensório-motores inatas ou de desenvolvimento precoce que nos colocam em relações com os outros e nos permitem interagir com eles. Estas capacidades manifestam-se ao nível da acção e da experiência perceptiva orientada para a acção - vemos ou, em geral, percepcionamos nos movimentos corporais, gestos, expressões faciais, direccionamento dos olhos, entoação vocal, etc., das outras pessoas, o que tencionam fazer e o que sentem, e respondemos com os nossos próprios movimentos corporais, gestos, expressões faciais, olhar, etc. A este respeito, a percepção é percepção-para-a-acção ou percepção em acção, e não observação desconectada. A criança é, desde o nascimento, atraída para estes processos interactivos. Isto pode ser visto desde muito cedo no comportamento do recém-nascido. As crianças são, desde o nascimento, capazes de percepcionar e imitar os gestos faciais apresentados por outrem (Meltzoff e Moore 1977; 1994). Significativamente, este tipo de imitação não é um processo automático ou mecânico; Csibra e Gergely (2009) mostraram, por exemplo, que a criança imita com maior probabilidade quando a outra pessoa está à espera disso.

A intersubjectividade primária pode ser especificada com maior pormenor à medida em que a criança se desenvolve. Com 2 meses, por exemplo, 
as crianças são capazes de seguir o olhar da outra pessoa, de ver que a outra pessoa está a olhar numa certa direcção, e de perceber o que a outra pessoa vê (que é por vezes a própria criança), de um modo que dá relevo à intenção da outra pessoa (Baron-Cohen 1995; Maurer e Barrera 1981). Além disso, a interacção com a segunda pessoa é evidenciada pelo tempo e pela reposta emocional no comportamento das crianças. Estas "vocalizam e gesticulam de um modo que parece [afectiva e temporalmente] 'sintonizado' com as vocalizações e gesticulações da outra pessoa" (Gopnik e Meltzoff 1997, 131). Murray e Trevarthen (1985) mostraram a importância da interacção da vida da mãe (e da sua vivacidade) com o seu bebé de dois meses numa experiência com monitores e câmaras de vídeo onde a mãe e a criança interagem através de uma ligação vídeo em directo. Quando é apresentada à criança uma gravação de acções prévias da mãe, a interacção falha; as crianças rapidamente se desinteressam, se distraem e ficam enervadas.

Entre os 5 e os 7 meses, as crianças são capazes de detectar correspondências entre informação visual e auditiva que especificam a expressão de emoções (Walker 1982; Hobson 1993). Com 6 meses, começam a perceber o movimento de preensão como dirigido a alvos, e com 10 ou 11 meses são capazes de compreender alguns tipos de acção contínua de acordo com parâmetros intencionais (Baldwin e Baird 2001; Baird e Baldwin 2001; Woodward e Sommerville 2000). Começam a percepcionar vários movimentos da cabeça, da boca, das mãos e movimentos corporais mais gerais como sendo significativos e dirigidos a alvos (Senju, Jonhson e Csibra 2006). Tudo isto é um somatório, de tal modo que ao fim do primeiro ano de vida as crianças possuem uma compreensão não-mentalizada, baseada na percepção, corporalizada e pragmática das emoções e das intenções das outras pessoas.

A intersubjectividade secundária começa com o advento da atenção conjunta (com cerca de 9 meses). Atender a objectos no mundo em conjunto com outrem e ver como são olhados e utilizados fornece à criança não só informação sobre o mundo, mas especificamente acerca das atitudes e acções dos outros. Assim, com cerca de 1 ano as crianças começam a usar os contextos pragmáticos e sociais (o ambiente envolvente e as várias práticas normativas que definem o meio social) de modo a aceder a um duplo processo. (1) Referem-se aos outros (numa referência social) e entram em acções conjuntas onde aprendem como os objectos são usados, utilizando-os e vendo os outros utilizá-los, e começam então a co-constituir o significado do mundo através de tais interacções com os outros num processo de "conferir sentido participativo" (De Jaegher e Di Paolo 2007); e (2) constroem sobre essas interacções de modo a conferir sentido ao comportamento dos outros em contextos específicos. 
Assim, ao situar as suas acções em contextos definidos tanto por tarefas pragmáticas quanto por práticas culturais, adquirem uma compreensão mais matizada dos outros.

Diversos aspectos da intersubjectividade secundária e do conferir sentido participativo foram explorados numa multiplicidade de experiências. Csibra e Gergely (2009), por exemplo, fornecem provas de que as crianças são sensíveis a sinais ostensivos (gestos, olhares e locuções) quando estes lhes são dirigidos por outra pessoa, e desenvolvem expectativas referenciais de que a informação veiculada (por exibição ou comunicação) em tais contextos é tipologicamente relevante e generalizável. As crianças, já com 8 meses, esperam ver um objecto referenciado quando seguem o olhar de outrem, e com 13 meses esperam ver um tipo específico de coisa atrás de uma barreira quando essa coisa é nomeada pela pessoa cujo olhar estão a seguir (Moll e Tomasello 2004). Quando uma criança de 14 meses vê uma manifestação emocional de outrem, dirigida a um determinado objecto, tomam isto como significando algo sobre a valência da coisa, e não como sobre a atitude subjectiva da outra pessoa, e generalizam isso de modo a significar que outros também acharão que o objecto tem a mesma valência (Csibra e Gergely 2009). Estas expectativas e interpretações só são evidentes, contudo, quando a outra pessoa interage com a criança de uma maneira ostensiva, ou seja, dirigindo-se ou olhando previamente para a criança. Csibra e Gergely chamam a isto uma "pedagogia natural", e isto é claramente um bom exemplo de um conferir sentido participativo onde os objectos adquirem um certo sentido por intermédio da interacção intersubjectiva.

Experiências com crianças de 18 meses mostram que estas são capazes de compreender as intenções de acção de outra pessoa que está a brincar com um brinquedo mas não consegue realizar alguma tarefa (por exemplo, se a outra pessoa tenta separar duas partes do brinquedo, mas falha). Se se lhes der a oportunidade, as crianças irão completar as acções tentadas (Meltzoff 1995). Nesta situação, a criança está focada sobretudo em compreender o que a outra pessoa quer fazer. A compreensão demonstrada numa tal situação depende claramente do contexto pragmático, bem como das acções corporais da outra pessoa.

Como sugerem Rackoczy et al. $(2009,445)$, a partir do primeiro ano, as acções que a criança aprende "não são somente comportamentos individuais, idiossincráticos, mas formas de acção convencionais e culturais. E muitas destas formas de acção são dirigidas por regras e estruturadas normativamente [...]." Mostram, nas suas experiências, que ao atingirem os 2 ou 3 anos, as crianças adoptam normas estritas sobre como jogar um certo jogo, seguindo regras estabelecidas arbitrariamente pelas expe- 
riências. As crianças objectam e protestam vivamente se uma boneca joga o jogo da maneira "errada", considerando que as acções da boneca não estão de acordo com a norma social.

\section{(b) Provas comportamentais e fenomenológicas}

Nem a intersubjectividade primária nem a secundária desaparecem depois do primeiro ou do segundo ano de vida. Estes não são estádios abandonados. Pelo contrário, com base tanto em provas comportamentais quanto fenomenológicas a TI argumenta que processos corporalizados de intersubjectividade primária e secundaria continuam a operar nas actividades sociais adultas e a caracterizar, mesmo quando adultos, os nossos encontros quotidianos. Ou seja, continuamos a compreender os outros em termos fortemente interactivos, favorecidos pelo nosso reconhecimento do significado das expressões faciais, gestos, posturas e acções, situados em contextos pragmáticos e sociais.

Experiências científicas confirmam-no. Experiências com pontos de luz (actores usam pontos de luz nas suas articulações corporais, apresentando assim no escuro padrões físicos abstractos de posturas emocionais e de acções), por exemplo, mostram que não só as crianças (as não autistas) como também os adultos percepcionam a emoção mesmo em movimentos que fornecem uma informação mínima (Hobson e Lee 1999; Dittrich et al. 1996). Uma análise pormenorizada da expressão facial, do gesto e da acção em contextos quotidianos mostra que continuamos, como adultos, a confiar em capacidades interactivas corporalizadas para compreender as intenções e acções dos outros e para realizar tarefas interactivas (Lindblom 2007; Lindblom e Ziemke 2007).

O significado e a significação emocional estão, por conseguinte, co-instituídos na interacção - e não nos confins privados das cabeças de um ou de outro. As análises das interacções sociais em actividades partilhadas, em situações de trabalho, em práticas comunicativas, etc., mostram que os agentes coordenam inconscientemente os seus movimentos, gestos e actos de fala (Issartel et al. 2007; Kendon 1990; Lindblom 2007). Nas práticas contextualizadas da intersubjectividade secundária, o tempo e a sintonização emocional continuam a ser importantes na medida em que coordenamos as nossas sequências acção-percepção: os nossos movimentos, por exemplo, estão acoplados a mudanças de velocidade, direcção e entoação dos movimentos e locuções do falante.

A noção husserliana de emparelhamento encontra algum apoio nas provas sobre o desenvolvimento e na continuação do comportamento adulto. As nossas acções estão desde a nascença codificadas na mesma 'linguagem' sensório-motora trans-modal, num sistema que está directamente 
sintonizado com as acções e os gestos de outros seres humanos (Meltzoff e Moore 1994; Gallagher e Meltzoff 1996). Neste tipo de interacção, conforme torna claro a noção de Merleau-Ponty de intercorporalidade, existe uma intencionalidade corporal (ou motora) distribuída através dos agentes em interacção, uma intencionalidade que não poderia ser realizada sem a ocorrência efectiva da interacção. O significado, a intencionalidade da acção individual reside na interacção. Ou seja, nos casos da interacção, as intenções de alguém não se formam unicamente no seu corpo individual, como resultado de um processo subjectivo isolado, mas dependem, de uma maneira dinâmica, das solicitações e respostas dos outros. A intercorporalidade envolve influência mútua de esquemas corporais, uma resposta dinâmica e enactiva [enactive] à acção de outrem, tomando esta acção como uma oportunidade para acções e interacções subsequentes.

\section{(c) Provas da modelação dinâmica de sistemas}

A modelação dinâmica dos sistemas e o uso de simulações em computador podem servir como suplementos tecnológicos úteis à metodologia fenomenológica (Froese e Gallagher 2010). Alguns teóricos têm utilizado tais abordagens para investigar o comportamento social mínimo. Iizuka e Di Paolo (2007), por exemplo, baseando o seu modelo no estudo de contingência com um vídeo de dois canais (já referido acima), de Murray e Trevarthen (1985), usaram uma abordagem de robótica evolucionista para mostrar que a detecção de contingências sociais emerge de uma dinâmica do próprio processo de interacção. No seu modelo de simulação, os agentes que evoluíram adquiriram com êxito a capacidade de discriminar entre relações 'vivas' (interactivas) e 'gravadas' (com uma só direcção, não interactivos). A análise dos sistemas dinâmicos demonstra que esta capacidade não pode ser reduzida ao agente individual isolado, mas que a dinâmica do próprio processo de interacção desempenha um papel essencial para a possibilidade deste comportamento. Quando os agentes tentam interagir com um 'parceiro' que não responde, cujos movimentos são somente repetidos a partir do registo de um encontro anterior altamente bem sucedido, a interacção não se materializa. Os actores individuais não realizam o desempenho da sua acção por meio de mecanismos computacionais internos, tais como 'módulos de detecção de contingência social'. Pelo contrário, o seu desempenho bem sucedido depende constitutivamente das propriedades dinâmicas envolvidas no seu acoplamento recíproco. O processo mútuo de dar e receber, de ir e vir faz, dos dois lados, a acção ser aquilo que é.

Nestes termos, a melhor forma de explicar a interacção social é a partir de uma perspectiva enactiva. Ou seja, como agentes corporalizados não 
recebemos informação passivamente do nosso ambiente e criamos então representações internas do mundo; pelo contrário, participamos activamente na geração do significado, o qual é o resultado de intercâmbios entre o agente e o ambiente (Varela et. al. 1991). No contexto intersubjectivo, a interacção envolve processos que vão além do que qualquer um dos indivíduos traz para a interacção (De Jaegher et al. 2010). Com efeito, assim como dançar o tango, a interacção não é redutível a um conjunto de mecanismos contidos dentro do indivíduo; são precisos pelo menos dois indivíduos corporalizados que estejam dinamicamente acoplados da maneira certa.

\section{A escala narrativa na cognição social}

As descrições fenomenológicas da cognição social fazem apelo a estes diferentes tipos de provas para apoiar um conceito robusto de interacção em contextos intersubjectivos primários e secundários. Porém, para se conhecer toda a história da cognição social, seria necessário acrescentar a estes processos de interacção competências cognitivas e narrativas (C\&N) que se desenvolvem mais tarde e que trazem consigo os aspectos mais subtis e sofisticados da cognição social que encontramos na idade adulta. Há também uma história de desenvolvimento que deve ser contada desde que as crianças pequenas 'pré-verbais' estão já envolvidas em práticas comunicativas significativas que envolvem o olhar, expressões faciais, respostas afectivas, gestos, apontar e comunicação verbal (por exemplo, a linguagem das mães com os bebés). Conforme aponta Merleau-Ponty (1987), a criança nasce num "turbilhão de linguagem", uma vez que não esperamos que as crianças "adquiram" a linguagem antes de começarmos a falar com elas. Além disso, em quase todas as culturas, o cuidador começará a contar histórias (por exemplo, canções, lenga-lengas, histórias infantis) às crianças mesmo antes que estas as possam compreender. Quando as crianças começam a verbalizar, um cuidador começará a suscitar as suas auto-narrativas (que envolvem já os outros) perguntando-lhes questões orientadoras sobre, por exemplo, 'o que fizemos ontem no zoológico?'

As crianças envolvem-se em práticas narrativas sob a forma de jogos imaginários. "As primeiras produções narrativas das crianças acontecem na acção, em episódios de jogo simbólico realizados em grupos de pares acompanhados pela linguagem - e não exclusivamente linguísticos. $\mathrm{O}$ jogo é uma fonte importante para o desenvolvimento da linguagem" (Nelson 2003 , p. 28). Isto mostra, significativamente, que a nossas competências $\mathrm{C} \& \mathrm{~N}$ emergem das nossas interacções. Assim, à medida que as práticas $\mathrm{C} \& \mathrm{~N}$ se desenvolvem, elas transportam as capacidades intersubjectivas 
primárias e secundárias e põem-nas ao serviço de contextos sociais muito mais sofisticados (veja-se Gallagher e Hutto 2008; Hutto 2008). Estas práticas, entretanto, não só dão forma às nossas faculdades reflexivas de compreender e dar razões para as nossas acções e para as acções dos outros, como também retroagem de modo a dar implicitamente forma aos nossos modos mais primários e pré-reflexivos de compreender os outros e as situações onde se encontram.

Nas descrições fenomenológicas, a tese é que a maior parte do que acontece nos nossos encontros quotidianos social-cognitivos com os outros podem ser explicados em termos de interacções intersubjectivas primárias e secundárias, e das nossas competências comunicativas e narrativas. $\mathrm{Na}$ maior parte das situações, não estamos a tentar ler a mente da outra pessoa; não estamos preocupados com os estados mentais das outras pessoas, embora tais preocupações possam ser motivadas por comportamentos relativamente incomuns, ou por tentativas de dar razão ou justificar acções reflexivamente. No entanto, mesmo em resposta a questões sobre porque alguém está a fazer algo (em oposição a simplesmente sobre o que está acontecer), explicações narrativas em termos de acções e situações são com frequências suficientes. Ainda quando conceitos de estados mentais entram na história, esta toma normalmente a forma de uma narrativa de psicologia popular e não de uma teoria psicológica popular (veja-se Hutto 2008).

\section{Revisitando a intersubjectividade transcendental}

Merleau-Ponty reconheceu uma forte conformação intersubjectiva da experiência, à qual, na sequência de Husserl, chamou "intersubjectividade transcendental". A sua tese era de que os processos intersubjectivos, que estão intimamente ligados à nossa experiência corporalizada e afectiva, dão forma ao modo como percepcionamos o mundo - e não somente à nossa percepção dos outros. Em termos da TI, parte do que isto significa pode ser apreendido no conceito de conferir sentido participante (De Jaegher e Di Paolo 2007). Aprendemos sobre o mundo e aprendemos como nos envolver com as coisas por intermédio da interacção e acção conjunta com os outros. Aprendemos o que é importante, o que é relevante, o que é aceitável, etc., justamente a partir destas interacções. A própria interacção é constitutiva deste significado. Pode o conferir sentido participante ser considerado como o equivalente naturalizado de algo como a constituição transcendental intersubjectiva do sentido e da objectividade do mundo? Se o problema da intersubjectividade transcendental pode ser naturalizado é uma questão controversa. A este respeito podemos, no entanto, guiar-nos mais uma vez por Merleau-Ponty. 
Ora, se o transcendental é a intersubjectividade, como podem as fronteiras do transcendental e do empírico deixar de se tornar indistintas? [...] Toda a minha facticidade é reintegrada na subjectividade [...]. Assim, o transcendental desce à história (Merleau-Ponty 1967, p. 107).

A este respeito, poder-se-ia argumentar que no contraste transcendental que indicámos entre Husserl e Heidegger, a facticidade está do lado de Husserl. Nos termos mais sucintos possíveis, não há lugar para a intersubjectividade primária na teoria de Heidegger. O seu ponto de partida é a intersubjectividade secundária. É somente em termos do nosso envolvimento em um projecto pragmático que encontramos os outros. Falta ao Mitsein de Heidegger um compromisso frente a frente, corporalizado e afectivo, com os outros. Ser-com os outros não é tanto ser com os outros, como estar empenhado em algum projecto que os envolve e, com efeito, de modos que nos atraem a todos para formas específicas de inautenticidade. Não há dúvida sobre a importância deste tipo de análises mas, se estas não tomam em linha de conta a intersubjectividade primária, facilmente deixam passar em claro certas possibilidades (talvez mesmo possibilidades de relações autênticas com os outros).

Do lado de Husserl, o conceito de intersubjectividade primária pode fornecer uma solução melhor do que o próprio Husserl oferece quanto ao problema da constituição transcendental da objectividade. Husserl apelou para um encontro primordial instituinte, o qual, como Zahavi põe a coisa, "torna de uma vez por todas possível a constituição da objectividade, da realidade e da transcendência" (Zahavi 2003, p. 116, itálicos acrescentados), mesmo que, por alguma razão, qualquer experiência subsequente com outros fosse excluída. É certo que a história mais correcta será que os nosso encontros instituidores estão a ocorrer e são explicados o mais adequadamente pelas práticas primárias e secundárias da intersubjectividade, onde a objectividade das entidades e dos acontecimentos está constantemente a ser instituída e reinstituída. O conferir sentido participativo é o resultado de interacções contínuas com outros, e o que conta como real não é determinado inteiramente fora da influência da história (como Merleau-Ponty faz notar) ou da cultura. O significado do mundo e a objectividade das entidades e dos acontecimentos dentro do mundo não são estabelecidos de uma vez por todas nem estão garantidos para sempre. Exemplos de ilusão perceptiva, bem como alucinações e ilusões patológicas dão testemunho justamente da possibilidade de perder uma tal apreensão objectiva e significativa do mundo.

$\mathrm{O}$ que quer que se pense destas questões, as abordagens fenomenológicas da intersubjectividade que incluem os recursos da psicologia do desenvolvimento, das ciências do comportamento e da simulação, assim 
como de outras ciências, pode certamente captar, no mínimo, a sombra empírica do transcendental.

\section{REFERÊNCIAS}

BAIRD, J. A., \& BALDWIN, D. A. (2001). Making sense of human behavior: Action parsing and intentional inference. In B. F. Malle, L. J. Moses, \& D. A. Baldwin (Eds.), Intentions and intentionality: Foundations of social cognition (193-206). Cambridge, MA: MIT Press.

BALDWIN, D. A., \& BAIRD, J. A. (2001). Discerning intentions in dynamic human action. Trends in Cognitive Science, 5(4), 171-178.

BARON-COHEN, S. (1995). Mindblindness: An Essay on Autism and Theory of Mind. Cambridge, MA: MIT Press.

BINSWANGER, L. (1962). Grundformen und Erkenntnis menschlichen Daseins. Ernst Reinhardt Verlag.

CARRUTHERS, P. (2009). How we know our own minds: the relationship between mindreading and metacognition. Behavioral and Brain Sciences 32 (2), 121-182.

CSIBRA, G. and GERGELY, G. (2009). Natural pedagogy. Trends in Cognitive Sciences 13, 148-53.

DE JAEGHER, H., and DI PAOLO, E. (2007). Participatory Sense-Making: An enactive approach to social cognition. Phenomenology and the Cognitive Sciences 6, 485-507

DE JAEGHER, H., DI PAOLO, E. and GALLAGHER, S. (2010). Does social interaction constitute social cognition? Trends in Cognitive Sciences 14 (10), 441-447.

DITTRICH, W.H., TROSCIANKO, T., LEA, S.E.G and MORGAN, D. (1996). Perception of emotion from dynamic point-light displays represented in dance. Perception 25, 727-38.

DREYFUS, H. (1991). Being-in-the-world: A Commentary on Heidegger's Being and Time, Division I. Cambridge, MA: MIT Press.

FROESE, T. and GALLAGHER, S. (2010). Phenomenology and artificial life: Toward a technological supplementation of phenomenological methodology. Husserl Studies 26 (2), 83-107.

FUCHS, T. and DE JAEGHER, H. (2009). Enactive intersubjectivity: Participatory sense-making and mutual incorporation. Phenomenology and the Cognitive Sciences 8, 465-486.

GADAMER, H-G. (2004). A Century in Philosophy: Hans-Georg Gadamer in Conversation with Riccardo Dottori. New York: Continuum.

GALLAGHER, S. (2008). Inference or interaction: Social cognition without precursors. Philosophical Explorations, 11 (3), 163-73. 
GALLAGHER, S. (2007). Simulation trouble. Social Neuroscience 2 (3-4), 353-65.

GALLAGHER, S. (2005). How the Body Shapes the Mind. Oxford: Oxford University Press/Clarendon Press.

GALLAGHER, S. (2004). Understanding problems in autism: interaction theory as an alternative to theory of mind. Philosophy, Psychiatry, and Psychology 11, 199-217.

GALLAGHER, S. (2001). The practice of mind: Theory, simulation or primary interaction? Journal of Consciousness Studies, 8(5-7), 83-108.

GALLAGHER, S. and HUTTO, D. (2008). Understanding others through primary interaction and narrative practice. In: J. Zlatev, T. Racine, C. Sinha and E. Itkonen (eds.), The Shared Mind: Perspectives on Intersubjectivity (17-38). Amsterdam: John Benjamins.

GALLAGHER, S. and JACOBSON, R. (in press). Heidegger and social cognition. In J. Kiverstein and M. Wheeler (eds.), Heidegger and Cognitive Science. London: Palgrave-Macmillan.

GALLAGHER, S., \& MELTZOFF, A. N. (1996). The earliest sense of self and others. Philosophical Psychology 9, 213-236.

GALLESE, V. (2003). The roots of empathy: The shared manifold hypothesis and the neural basis of intersubjectivity. Psychopathology 36,171-180

GOLDMAN, A. I. (2006). Simulating Minds: The Philosophy, Psychology, and Neuroscience of Mindreading. New York: Oxford University Press.

GOLDMAN, A. I. (2005). Imitation, mind reading, and simulation. In: S. Hurley and N. Chater (eds.), Perspectives on imitation II (80-91). Cambridge, MA: MIT Press.

GOPNIK, A. and MELTZOFF, A. N. (1997). Words, Thoughts, and Theories. Cambridge, MA: MIT Press.

HEIDEGGER, M. (1985). History of the concept of time. Bloomington: Indiana University Press.

HEIDEGGER, M. (1988). The Basic Problems of Phenomenology, A. Hofstadter (trans). Bloomington: Indiana University Press.

HEIDEGGER, M. (1962). Being and Time, Trans. J. Macquarrie and E. Robinson. New York: Harper \& Row. Cited with English/German pagination.

HEIDEGGER, M. (1993). Sein und Zeit, Tübingen: Max Niemeyer.

HOBSON, P. (1993). The emotional origins of social understanding. Philosophical Psychology 6, 227-249.

HOBSON, P. and LEE, A. (1999). Imitation and identification in autism. Journal of Child Psychology and Psychiatry 40, 649-59.

HUSSERL, E. (1977). Phenomenological Psychology: Lectures, Summer Semester, 1925. Trans. J. Scanlon. The Hague: Martinus Nijhoff. German pagination in margins.

HUSSERL, E. (1973). Zur Phänomenologie der Intersubjektivität III, Husserliana XV. Den Haag: Martinus Nijhoff. 
HUSSERL, E. (1960). Cartesian Meditations: An Introduction to Phenomenology. Trans. D. Cairns. Den Haag: Martinus Nijhoff.

HUTTO D. D. (2008). Folk Psychological Narratives: The Socio-Cultural Basis of Understanding Reasons. Cambridge, MA: MIT Press.

IIZUKA, H. and DI PAOLO, E. A. (2007). Minimal agency detection of embodied agents. In F. Almeida e Costa, L. M. Rocha, E. Costa, I. Harvey \& A. Coutinho (Eds.), Advances in Artificial Life: Proc. of the 9th Euro. Conf. on Artificial Life (485-494). Berlin, Germany: Springer.

ISSARTEL, J., MARIN, L., and CADOPI, M. (2007). Unintended interpersonal coordination: 'Can we march to the beat of our own drum'? Neuroscience Letters 411, 174-179.

KENDON, A. (1990). Conducting Interaction: Patterns of Behavior in Focused Encounters. Cambridge: Cambridge University Press.

LEVINAS, E. (1969). Totality and Infinity: An Essay on Exteriority. Trans. A. Lingis, Pittsburgh, PA: Duquesne University Press.

LINDBLOM, J. (2007). Minding the Body: Interacting socially through embodied action. Linköping Studies in Science and Technology. Dissertation No. 1112 Linköpings universitet.

LINDBLOM, J. and ZIEMKE, T. (2007). Embodiment and social interaction: implications for cognitive science. In T. Ziemke, J. Zlatev and R. Frank (Eds.), Body, Language, and Mind: Embodiment (129-162). Berlin: Mouton de Gruyter.

LÖWITH, K. (1928). Das Individuum in der Rolle des Mitmenschen. In K. Stichweh (ed.), Sämtliche Schriften, Vol. 1. (9-197). Stuttgart: J. B. Metzler, 1981.

MAURER, D. and BARRERA, M. E. (1981). Infants' perception of natural and distorted arrangements of a schematic face. Child Development 52 (1), 196-202.

MELTZOFF, A. N. (1995). Understanding the intentions of others: Re-enactment of intended acts by 18-month-old children. Developmental Psychology 31, 838-850.

MELTZOFF, A. and MOORE, M. K. (1977). Imitation of facial and manual gestures by human neonates. Science 198, 75-78.

MELTZOFF, A. and MOORE, M. K. (1994). Imitation, memory, and the representation of persons. Infant Behavior and Development 17, 83-99.

MERLEAU-PONTY, M. (1987). Signs. Trans. R. C. McCleary. Evanston: Northwestern University Press.

MERLEAU-PONTY, M. (1968). The Visible and the Invisible. Trans. A. Lingis. Evanston: Northwestern University Press.

MERLEAU-PONTY, M. (1967). The Structure of Behaviour. Boston: Beacon Press.

MERLEAU-PONTY, M. (1962). Phenomenology of Perception. Trans. C. Smith. London: Routledge and Kegan Paul. 
MOLL, H. and TOMASELLO, M. (2004). 12- and 18-month-old infants follow gaze to spaces behind barriers. Developmental Science 7, F1-F9.

MURRAY, L. and TREVARTHEN, C. (1985). Emotional regulations of interactions between two-month-olds and their mothers. In T. M. Field and N. A. Fox (eds.), Social perception in infants (177-197). Norwood, NJ: Ablex Publishing.

NELSON, K. (2003). Narrative and the emergence of a consciousness of self. In Narrative and Consciousness, ed. G. D. Fireman, T. E. McVay, Jr. O. J. Flanagan. New York: Oxford University Press.

PÖGGELER, O. (1989). Martin Heidegger's Path of Being. Trans. D. Magurshak and S. Barber. Atlantic Highlands, NJ: Humanities Press.

RAKOCZY, H., BROSCHE, N., WARNEKEN, F. and TOMASELLO, M. (2009). Young children's understanding of the context-relativity of normative rules in conventional games. British Journal of Developmental Psychology 27, 445-456.

RATClifFE, M. (2007). Rethinking Commonsense Psychology: A Critique of Folk Psychology, Theory of Mind and Simulation. Basingstoke: Palgrave Macmillan.

REDDY, V. (2008). How Infants Know Minds. Cambridge, MA: Harvard University Press

SARTRE, J.-P. (1956). Being and Nothingness. Trans. H.E. Barnes. New York: Philosophical Library.

SENJU, A., JOHNSON, M. H., \& CSIBRA, G. (2006). The development and neural basis of referential gaze perception. Social Neuroscience 1(3-4), 220-234.

STEUBER, K. A. (2006). Rediscovering Empathy: Agency, Folk-Psychology and the Human Sciences. Cambridge, MA: MIT Press.

TREVARTHEN, C. B. (1979). Communication and cooperation in early infancy: A description of primary intersubjectivity. In M. Bullowa (ed.), Before Speech (321-48). Cambridge: Cambridge University Press.

TREVARTHEN, C. and HUBLEY, P. (1978). Secondary intersubjectivity: Confidence, confiding and acts of meaning in the first year. In A. Lock (ed.), Action, Gesture and Symbol: The Emergence of Language (183-229). London: Academic Press.

VARELA, F., THOMPSON, E. and ROSCH, E. (1991). The Embodied Mind: Cognitive Science and Human Experience. Cambridge, MA: MIT Press.

WALKER, A. S. (1982). Intermodal perception of expressive behaviors by human infants. Journal of Experimental Child Psychology 33, 514-535.

WHEELER, M. (2005). Reconstructing the Cognitive World: The Next Step. Cambridge, MA: The MIT Press.

WOODWARD, A. L., and SOMMERVILLE, J. A. (2000). Twelve-month-old infants interpret action in context. Psychological Science 11, 73-77. 
ZAHAVI, D. (2012b). Empathy and mirroring: Husserl and Gallese. In R. Breeur \& U. Melle (eds.), Life, Subjectivity \& Art: Essays in Honor of Rudolf Bernet (217-254). Dordrecht: Springer.

ZAHAVI, D. (2003). Husserl's Phenomenology. Stanford, CA: Stanford University Press. 